(C) [2009] IEEE. Reprinted, with permission, from [Felician J More, Kevin Weng, Peter Mclean and Steven Su, Analysis of Nonlinear and Linear Behaviors of Heart Rate for Running Exercise, Industrial Electronics and

Applications, 2009. ICIEA 2009. 4th IEEE Conference on, ICIEA 2009. 4th IEEE Conference on, 25-27 May 2009]. This material is posted here with permission of the IEEE. Such ermission of the IEEE does not in any way imply IEEE endorsement of any of the University of Technology, Sydney's products or services. Internal or personal use of this material is permitted. However, permission to reprint/republish this material for advertising or promotional purposes or for creating new collective works for resale or redistribution must be obtained from the IEEE by writing to pubspermissions@ieee.org. By choosing to view this document, you agree to all provisions of the copyright laws protecting it 


\title{
Analysis of Nonlinear and Linear Behaviors of Heart Rate for Running Exercise
}

\author{
Felician J More*, Kevin Weng, Peter Mclean, Steven Su \\ Faculty of Engineering and Information Technology, University of Technology, Sydney, NSW 2007, Australia \\ *Email addresses: Felician.More@uts.edu.au
}

\begin{abstract}
This study investigates the nonlinear/linear behaviors of human heart rate response to treadmill exercise, for young and healthy subjects. The heart rate of the subject is measured, starting at a speed of $7 \mathrm{~km} / \mathrm{h}$, and increasing until the maximum heart rate for the subject is reached. The obtained nonlinear model is complicated and is not robust. Furthermore, sustained exercise at maximum heart rate is not always safe. For these reasons, this is not a suitable method for running exercise. Instead, we develop simple linear models for the same speed range, which is suitable for treadmill running exercise. We also propose a new model, called ' $\mathrm{H}$ model', to predict the percentage of heart rate reserve during running exercise. It has been proven that the presented model can predict the percentage change of heart rate for running exercise in the identified linear response range.
\end{abstract}

Index Terms-Curve fitting, Nonlinear systems, Human cardiovascular system, Heart rate.

\section{INTRODUCTION}

Cardiac responses to exercise are used in testing to monitor the progress of the exercise program. Exercise testing includes experimental data collection and preprocessing, physiological variable analysis, and training protocol design. Specific exercises can be recommended for each individual depending upon their own interests. In this study, we investigate treadmill running due to its popularity.

Cardio-respiratory fitness for an individual can be enhanced by the use of aerobic exercise at an appropriate intensity. Heart rate (HR) is one of the most commonly used non-invasive measurements of exercise intensity for healthy adults. The American College of Sports Medicine (ACSM) has invented the exercise intensity program, and this could be defined as a percentage of maximal heart rate (ACSM, 2000) [7].

Researchers have found that the percentage of heart rate reserve (defined as the difference between maximal and resting heart rate), often provides a more accurate measurement of exercise intensity. Percentage of heart rate reserve is the precise representative of the net energy expenditure [11], and it is considered to be a predictor for energy expenditure [11] [12]. Therefore, monitoring the percentage of heart rate reserve is a way of examining exercise, and the heart rate response model is a significant assessment of the physical health of individuals [3].

There are nonlinear dynamic models for heart rate response to treadmill walking exercises, both in the exercising and recovery stages. Researchers often model heart rate behavior from a regulation point of view [1] [2] [4] [5]. This paper explores the steady state nonlinear/linear behavior of heart rate response for running exercise. The linear range of heart rate response has been identified, and a new model, called ' $\mathrm{H}$ model', has been proposed to predict the change of percentage of heart rate reserve, during running exercise.

The organization of the paper is as follows. In Section II, the proposed modeling method is introduced. Experimental validation is given in Section III. Section IV concludes the paper.

\section{PROPOSED H MODEL}

The following model has been proposed to illustrate the heart rate response with respect to speed, for running exercise.

$$
\% H_{R}=\left[\frac{H}{\text { Hrest }}-1\right] \times 100
$$

Where Hrest is the resting heart rate, and $H_{R}$ is the heart rate at any instant. $\% H_{R}$ is the model heart rate in percentage.

Resting heart rate, was defined for each subject, and was obtained by resting for a period of 3 minutes between exercises.

\section{EXPERIMENTAL VERIFICATION}

\section{A. Subjects}

One healthy female and four male subjects were studied. The physical characteristics of the subjects are summarized in Table I.

\section{B. Procedure}

Each subject had completed running exercise sessions on separate occasions. The male and female subjects undertook running exercise sessions in the same environment. All subjects ran on the same treadmill for this experiment.

In each session, the subject was requested to run on the treadmill at given speeds $(7 \mathrm{~km} / \mathrm{h}, 8 \mathrm{~km} / \mathrm{h}, 9 \mathrm{~km} / \mathrm{h}, 10 \mathrm{~km} / \mathrm{h}$, $11 \mathrm{~km} / \mathrm{h}$, and $12 \mathrm{~km} / \mathrm{h}$ ) for five minutes, with a recovery period of 15 minutes in each.

The subject's resting heart rate was monitored for 3 minutes before starting to run on the treadmill. The heart rate was then monitored while the subject ran at the given speed for 5 
minutes. Lastly, the recovering heart rate has been monitored for 20 minutes after the end of running exercise. The period of each exercise would take up to 23minutes for a given speed. The subjects were required to stand during rest in order to obtain the data.

TABLE I. PHYSICAL CHARACTERISTICS OF THE SUBJECTS: AGE, HEIGHT, WEIGHT AND BMI (BODY MASS INDEX)

\begin{tabular}{|l|l|l|l|l|}
\hline Subject & Age & Height (cm) & Weight (kg) & BMI \\
\hline 1 & 24 & 177 & 65 & 20.2 \\
\hline 2 & 21 & 168 & 65 & 23 \\
\hline 3 & 27 & 160 & 70 & 27.3 \\
\hline 4 & 34 & 165 & 55 & 20.2 \\
\hline 5 & 30 & 180 & 65 & 20.1 \\
\hline
\end{tabular}

\section{Data acquisition and pre-processing}

In this study, the heart rate of the subject was monitored by the wireless Polar system, and recorded by the Polar S625 Wrist unit. The unwanted electromagnetic interferences from external sources, (e.g. high voltage power lines, televisions, other heart rate monitors, and in some cases mobile phones), often generate disturbance in the measured heart rate data. The outliers were removed, as much as possible, by eliminating these external sources in the area surrounding the exercise environment, so that the measured heart rate data would not be affected. The heart rate data was stored in the Wrist Unit.

\section{Results}

1) A non-linear dynamic model for heart rate response for running exercise

The non-linear model for the heart rate response of running exercise has been obtained from Subject 5 only. Subject 5 was requested to run on a treadmill at a given speed $(7 \mathrm{~km} / \mathrm{h}, 8 \mathrm{~km} / \mathrm{h}$, $9 \mathrm{~km} / \mathrm{h}, 10 \mathrm{~km} / \mathrm{h}, 11 \mathrm{~km} / \mathrm{h} .$. and $15 \mathrm{~km} / \mathrm{h}$ ) for five minutes with a recovery period of 15 minutes. The subject completed three exercise sessions in separate occasions. The average rest heart rates for the subject 5 are given below Table.

TABLE II. AVERAGE REST HEART RATE OF SUBJECT 5

\begin{tabular}{|l|l|}
\hline \multicolumn{1}{|c|}{ Session } & Average Rest Heart Rate (bpm) \\
\hline 1 & 123 \\
\hline 2 & 110 \\
\hline 3 & 122 \\
\hline
\end{tabular}

Figure 1 depicts the non-linearity behavior of the heart rate responses.

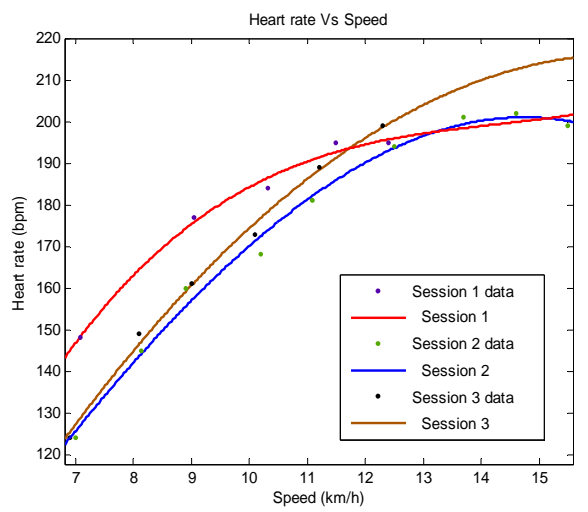

Figure 1. Heart rate responses of Subject 5

Figure 2 shows that the proposed H Model also depicts nonlinearity of heart rate response.

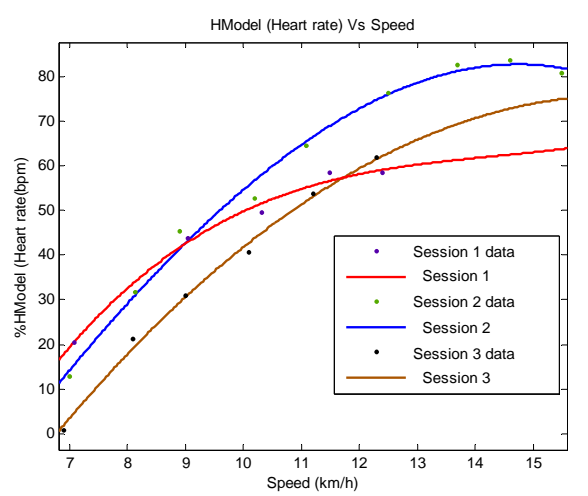

Figure 2. Percentage H Model Heart rate responses of Subject 5

The following table below reveals that $\mathrm{H}$ Model is a better model for describing the non-linearly of the dynamic heart rate response for running exercise. The $\mathrm{H}$ model has less SSE. To prove that $\mathrm{H}$ Model is a more appropriate model for non-linear dynamic heart rate response for running exercise, more experiments are needed at high running speeds. Furthermore, we also found that non-linear range for running exercise is not suitable for practical purposes because it is not considered to be a healthy exercise for the heart. We detect linear range of heart rate response next.

TABLE III. MODEL COMPARISION

\begin{tabular}{|l|l|l|l|l|}
\hline $\begin{array}{c}\text { Model } \\
\text { type }\end{array}$ & Sessions & \multicolumn{1}{c|}{ SSE } & R-Square & \multicolumn{1}{c|}{ RMSE } \\
\hline Normal & Session 1 & 14.00456 & 0.99064 & 3.74227 \\
\hline H Model & & 9.27340 & 0.99066 & 3.04523 \\
\hline Normal & Session 2 & 49.40514 & 0.99197 & 3.14341 \\
\hline H Model & & 40.76819 & 0.99198 & 2.85546 \\
\hline Normal & Session 3 & 15.54699 & 0.99585 & 2.27647 \\
\hline Model & & 10.29084 & 0.99584 & 1.85210 \\
\hline
\end{tabular}


The linear range for heart- rate response for running exercise was determined as from $7 \mathrm{~km} / \mathrm{h}$ to $13 \mathrm{~km} / \mathrm{h}$. Table IV gives the average rest heart rate for each subject.

TABLE IV. AVERAGE REST HEART RATES OF SUBJECTS

\begin{tabular}{|l|l|}
\hline \multicolumn{1}{|c|}{ Subject } & Average Rest Heart Rate (bpm) \\
\hline 1 & 106.4 \\
\hline 2 & 131.02 \\
\hline 3 & 79.50 \\
\hline 4 & 68.00 \\
\hline 5 & 123.00 \\
6 & 110 \\
\hline
\end{tabular}

2) Estimate a slope for a linear range - Absence of $H$ Model

Each subject's change in heart rate response has been analyzed with respect to speed in the absence of H Model and plotted.

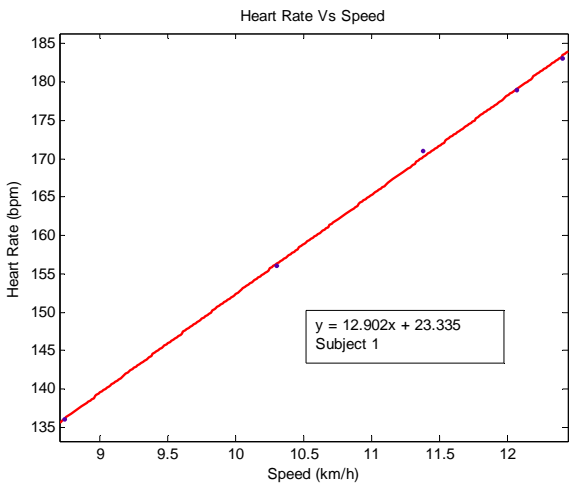

Figure 3. Heart rate responses of Subject 1

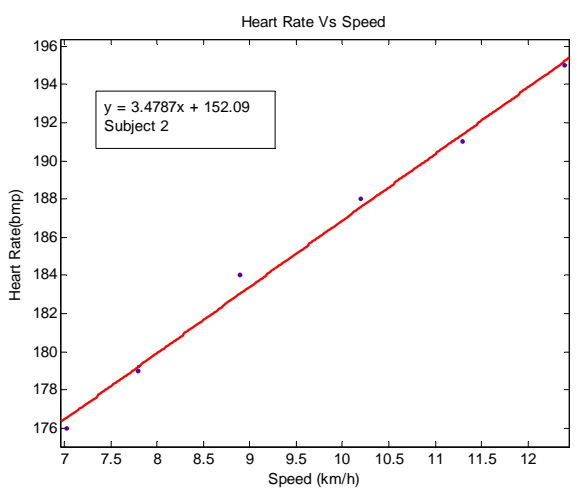

Figure 4. Heart rate responses of Subject 2

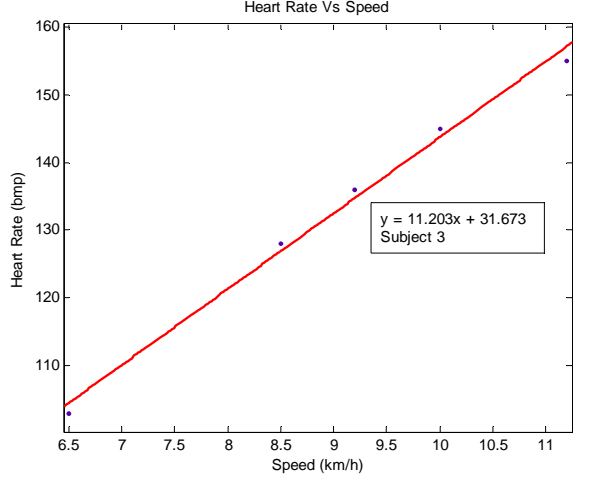

Figure 5. Heart rate responses of Subject 3

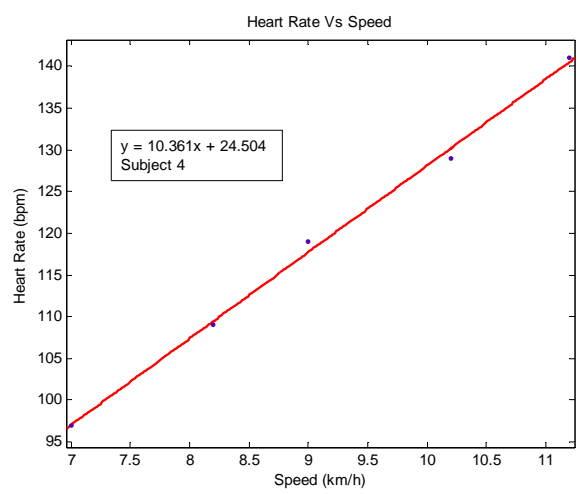

Figure 6. Heart rate responses of Subject 4

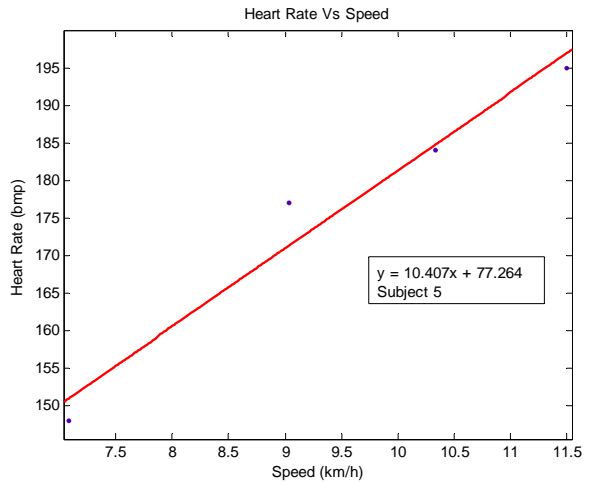

Figure 7. Heart rate responses of Subject 5 (I)

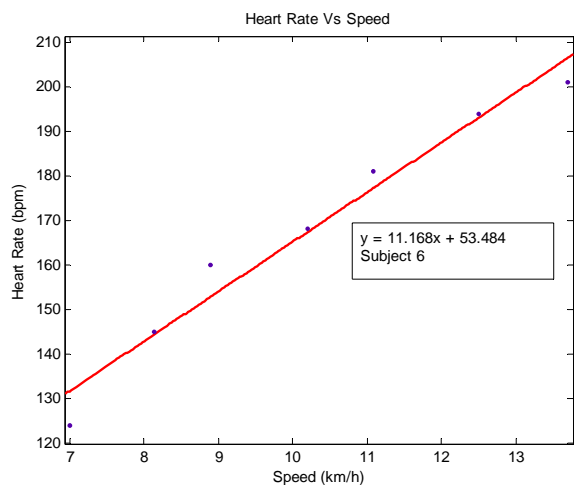

Figure 8. Heart rate responses of Subject 5 (II) 
The Table below shows an analysis of the mean and standard deviations of the subjects' change of heart rate response with the increase in speed.

TABLE V. CHANGE OF HEART RATE S FOR 6 DIFFERENT SUBJECTS WITHOUT H MODEL

\begin{tabular}{|c|c|c|c|c|c|c|c|}
\hline Subject & $\mathbf{1}$ & $\mathbf{2}$ & $\mathbf{3}$ & $\mathbf{4}$ & $\mathbf{5}$ & $\mathbf{6}$ & \\
\hline Slope & 12.90 & 3.4787 & 11.203 & 10.361 & 10.407 & 11.168 & \\
\hline Mean & & & & & & & 9.92 \\
\hline STD & & & & & & & 3.28 \\
\hline
\end{tabular}

The following figure shows the linear model for running exercise with the absence of $\mathrm{H}$ Model with combined data.

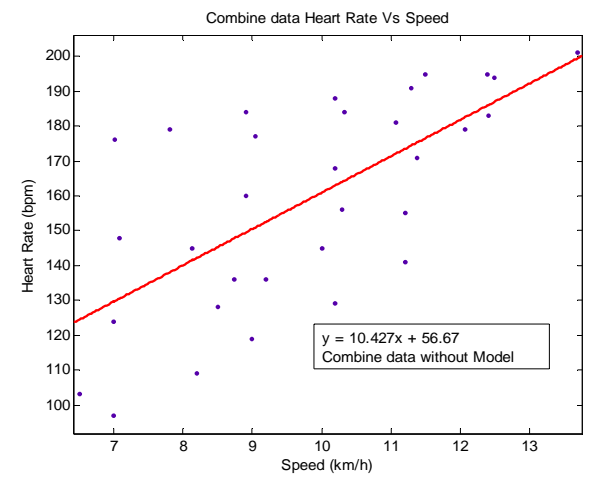

Figure 9. Heart rate responses of combine data

3) Estimate a slope for a linear range - Presence of $H$ Model

The slope of a linear range for running exercise has been analyzed with the $\mathrm{H}$ Model. Each subject's change in heart rate response has been analyzed with respect to speed in the absence and plotted. The following figures show below.

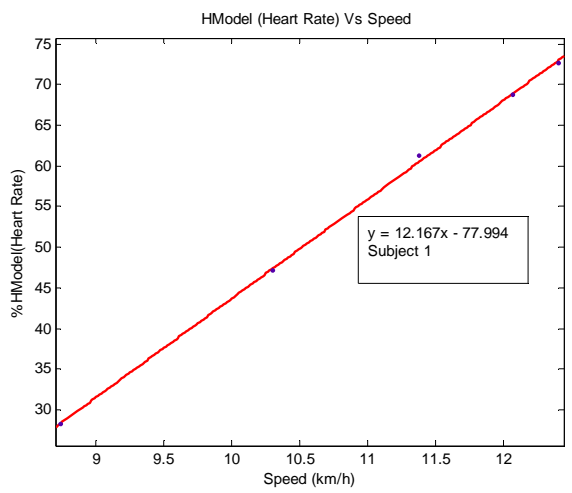

Figure 10. Percentage H Model Heart rate responses of Subject 1

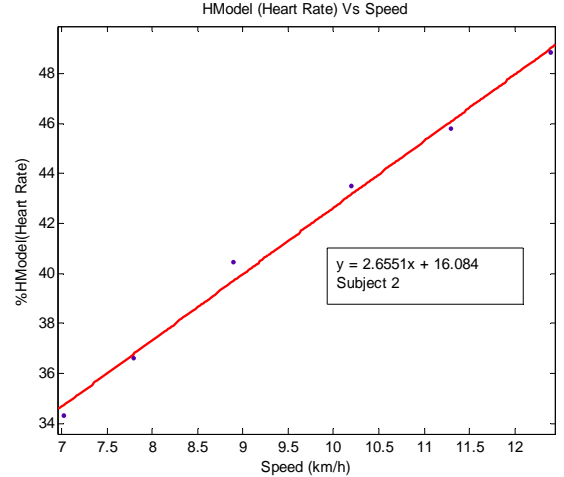

Figure 11. Percentage H Model Heart rate responses of Subject 2

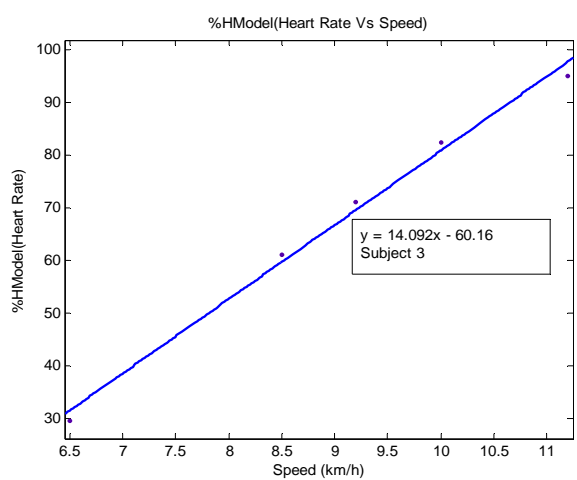

Figure 12. Percentage H Model Heart rate responses of Subject 3

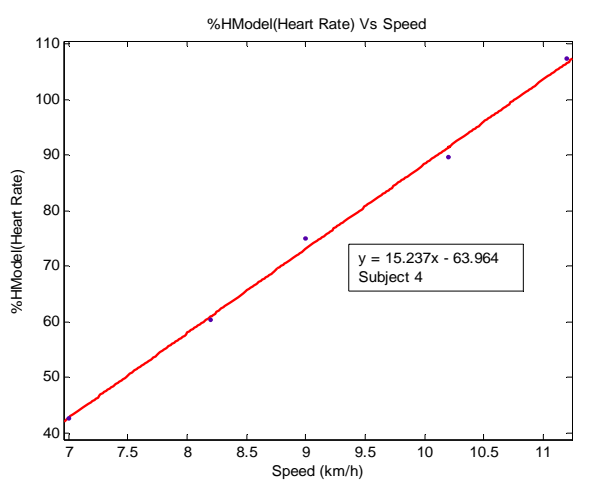

Figure 13. Percentage H Model Heart rate responses of Subject 4

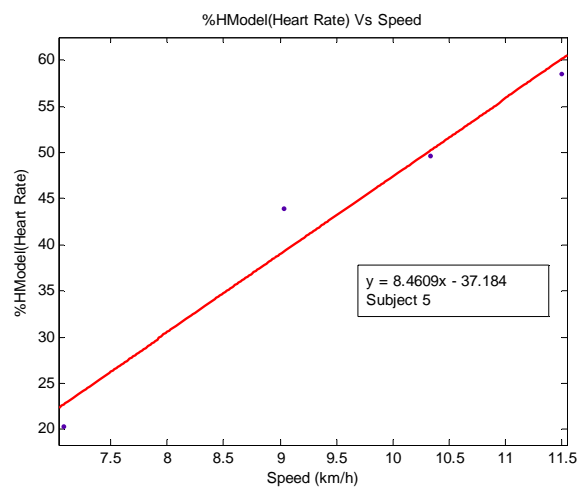

Figure 14. Percentage H Model Heart rate responses of Subject 5 (I) 


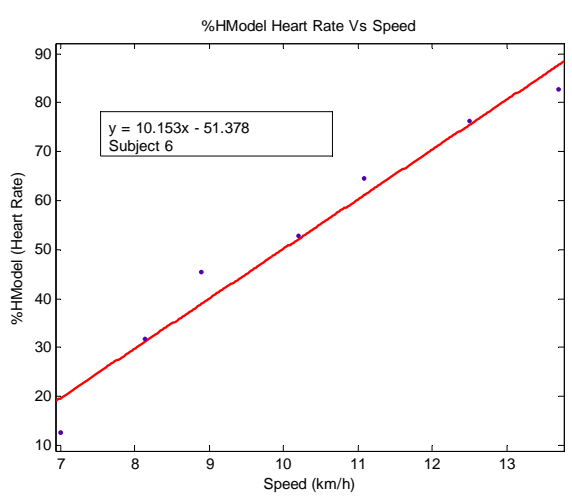

Figure 15. Percentage H model Heart rate responses of Subject 5 (II)

The Table below summarizes the mean and standard deviations of the subjects' change of heart- rate response with increase in speed.

TABLE VI. CHANGE OF HEART RATE S FOR 6 DIFFERENT SUBJECTS WITH H MODEL

\begin{tabular}{|c|l|l|l|l|l|l|l|}
\hline Subject & 1 & 2 & 3 & 4 & 5 & 6 & \\
\hline Slope & 12.17 & 2.6551 & 14.092 & 15.237 & 8.4609 & 10.153 & \\
\hline Mean & & & & & & & 10.46 \\
\hline STD & & & & & & & 4.559 \\
\hline
\end{tabular}

\section{4) Estimate a slope for a linear range - Combined data}

The following figure shows the combined data of all subject's with the absence of H Model.

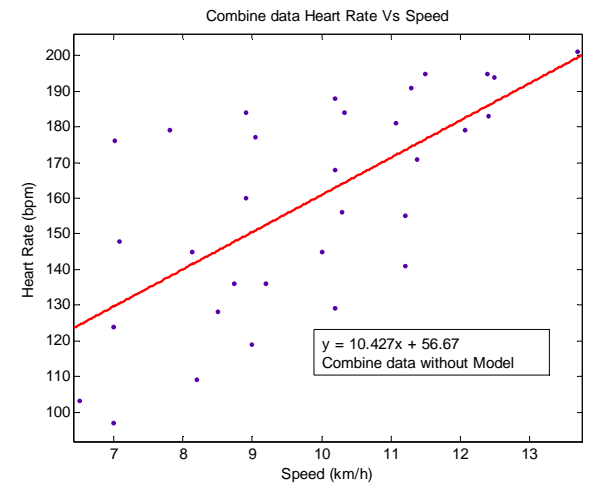

Figure 16. Heart rate responses for 5 different subjects
The following figure shows the combined data of all subject's with H Model.

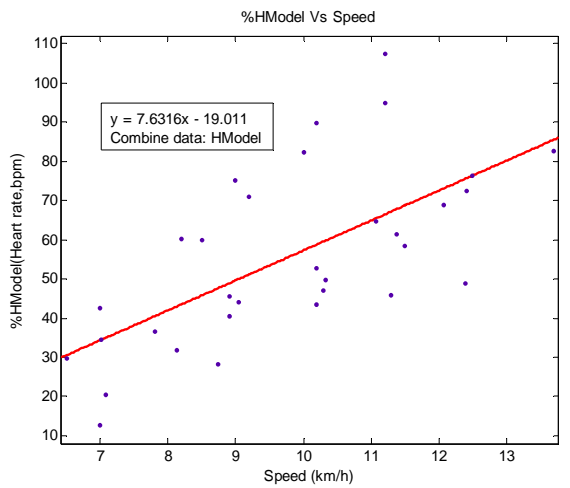

Figure 17. Percentage Heart rate responses for 5 different subjects

\section{5) Comparison between the with and without $H$ model}

The following table analysis the experimental result for the linear model for heart rate response to running exercise with and without the $\mathrm{H}$ Model for each subjects and a unified model for all data.

TABLE VII. MODEL ERROR

\begin{tabular}{|l|l|l|l|}
\hline \multicolumn{1}{|c|}{ Subject } & \multicolumn{1}{c|}{ SSE } & \multicolumn{1}{c|}{ R Square } & \multicolumn{1}{c|}{ RMSE } \\
\hline 1 & 0.971892 & 0.999342 & 0.569178 \\
\hline 2 & 1.605352 & 0.993861 & 0.633512 \\
\hline 3 & 17.91017 & 0.992749 & 2.44337 \\
\hline 4 & 3.383481 & 0.997103 & 1.061992 \\
\hline $5(\mathrm{I})$ & 45.04618 & 0.962772 & 4.74585 \\
\hline $5(\mathrm{II})$ & 155.4411 & 0.965161 & 5.57568 \\
\hline
\end{tabular}

TABLE VIII. MODEL ERROR

\begin{tabular}{|l|l|l|l|}
\hline Subject & \multicolumn{1}{|c|}{ H Model SSE } & \multicolumn{1}{|c|}{$\begin{array}{c}\text { H Model R } \\
\text { Square }\end{array}$} & \multicolumn{1}{c|}{$\begin{array}{c}\text { H Model } \\
\text { RMSE }\end{array}$} \\
\hline 1 & 0.864444 & 0.999342 & 0.536794 \\
\hline 2 & 0.941401 & 0.993819 & 0.485129 \\
\hline 3 & 11.31697 & 0.992751 & 1.942247 \\
\hline 4 & 7.304341 & 0.997108 & 1.560378 \\
\hline $5(\mathrm{I})$ & 29.72294 & 0.962829 & 3.855058 \\
\hline $5(\mathrm{II})$ & 128.3702 & 0.965185 & 5.066957 \\
\hline
\end{tabular}

The above table clearly shows that $\mathrm{H}$ Model is a new model to describe the linear model for heart rate response with the increase of speed in the linear range, and that the $\mathrm{H}$ Model has the least values of SSE and RMSE than the model without the H Model.

Similarly, we have also found that the $\mathrm{H}$ Model has a better linear relationship with heart rate response for running exercise. Vide the comparison table below. 
TABLE IX. COMPARISION BETWEEN TWO MODELS

\begin{tabular}{|c|c|c|c|}
\hline & SSE & R Square & RMSE \\
\hline $\begin{array}{c}\text { Combined data with H } \\
\text { Model }\end{array}$ & 8873.159 & 0.425521 & 17.19802 \\
\hline $\begin{array}{c}\text { Combined data without } \\
\text { Model }\end{array}$ & 15243.49 & 0.445232 & 22.54144 \\
\hline
\end{tabular}

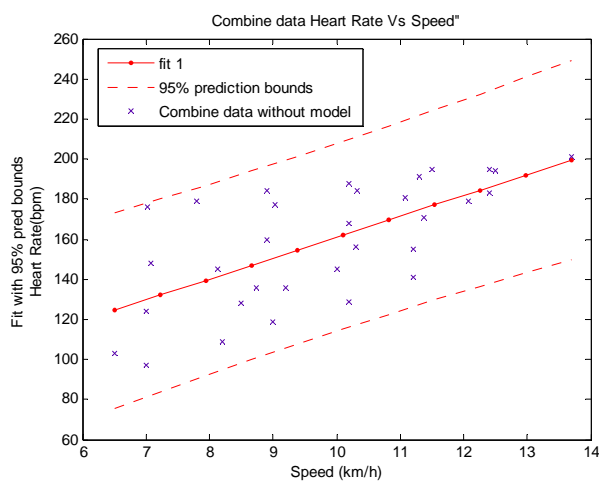

Figure 18. 95\% of confidence levels of data were in bound

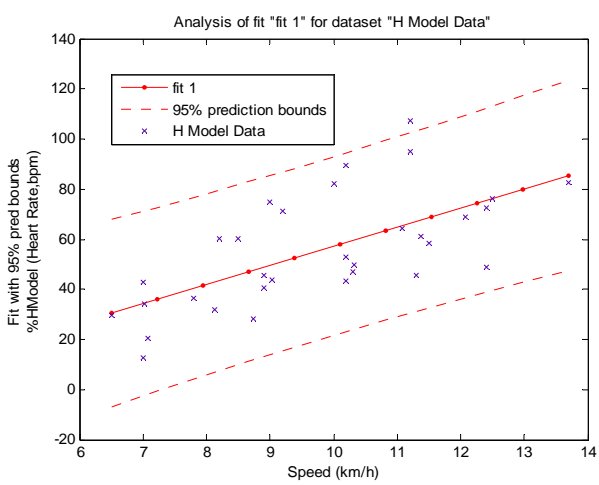

Figure 19. 95\% of confidence levels of data were in bound with H model

In comparison of unified models that $\mathrm{H}$ model has least SSE and RMSE; the above figures reveal that 95\% of confidence levels of data were in bound with model.

The linear heart rate responses $\mathrm{H}$ model for the different subjects to perform their regular running exercise. The subject requires monitoring their rest heart rate before commencing an exercise session. The percentage of Heart rate responses can be estimated with the use of the following equations.

- $\quad$ Unified $\mathrm{H}$ model for linear range heart rate response is given below

$$
\begin{aligned}
& \% \text { H(Heart Rate }(\mathrm{bpm})) \\
& =7.6316 \times \text { Speed }(\mathrm{km} / \mathrm{h})-19.011
\end{aligned}\left\{\begin{array}{l}
7 \leq \text { Speed } \leq 13 \\
\text { Speed } \neq 0
\end{array}\right\}
$$

- $\quad$ Unified H model for both linear and nonlinear heart rate for running exercise is given below

$$
\% H_{R}=\left[\frac{H}{\text { Hrest }}-1\right] \times 100
$$

\section{CONCLUSION}

In this study, we have identified the linear response range of heart rate, for treadmill running exercises. In order to estimate the percentage of heart rate reserve, we introduce $\mathrm{H}$ Model. The results clearly show that $\mathrm{H}$ Model provides accurate estimations of heart rate responses for healthy individuals. We suggest treadmill running exercise should be confined to the identified linear response range for a given subject.

\section{REFERENCES}

[1] V. Brodan, M. hajek, and E Kuhn, "An analog model of pulse rate during physical load and recovery” Physiologia Bohemoslovaca, Vol.20 pp. 189-198, 1971.

[2] M. hajek, J Potucek, and V.Brodan, "Mathematical model of heart rate regulation during exercise”, Automatica, Vol. 16, pp.191-195,1980.

[3] J.Achten and A.E. Jeukendrup, "Heart rate monitoring: Applications and limitations,” Sports Med, Vol.33, no. 7, pp. 517-538, 2003.

[4] Teddy M. Cheng, Andrey V. Savkin, Branko G. Celler, Steven W. Su, and Lu Wang, Nonlinear modelling and control of human heart rate response during exercise with various work load intensities, IEEE Trans. Biomed. Eng., VOL.55, NO.11, pp2499-2508, 2008.

[5] S.W. Su, S. Huang, L. Wang, B.G. Celler, A.V. Savkin, Y. Guo and T. Cheng. Nonparametric Hammerstein Model Based Model Predictive Control for Heart Rate Regulation, in Proceedings of EMBC, Pages 2984-2987, Aug 23-26, 2007, Lyon, France

[6] Londeree, B.R, T.R. Thomas, G.Ziogas, T.D. Smith , Z. Zhang. \%Vo2max versus \%1-iRmax regressions for six modes of exercise. Med.Sci.Sport. Exerc, 27:458-461,1995.

[7] American college of Sport Medicine (2000).ACSM's Guidelines for Exercise testing and Prescription (6’h ed), Philadelphia, P.A: Lippcott Williams \& Wilkins.

[8] Ceci, R, \& P. Hassmen. Self monitoring exercise at three different RPE Intensities in treadmill vs field running. Med.Sci.Sports. Exerc.23:732738,1991.

[9] Bassett, D.R, M.D giese, F.J. Nagle, A. Ward, D.M.Raab \&B. Balke. "Aerobic requirements of overground versus treadmill running" Med. Sci. Sports .Exerc., 17:477-481, 1985.

[10] Meyer, T, I.P. Welter, J Sharhag \& W. Kindcrmann. Maximal oxygen uptake during field running does not exceed that measured during treadmill exercise. Eur. J. Appl Physiol., 88:387-389, 2003.

[11] Strath, S.J, A. M. Swartz. D.R. Bassett, W.L O’brien, G.A. King \& B.E. Ainsworth. "Evaluation of heart rate as a method for assessing moderate intensity of physical activity. Med. Sci. Sports. Exerc, 32:S465-S470, 2000.

[12] Swain, D.P, \& B.C Leutholtz, Heart rate reserve is equivalent to \%Vo2 reserve, not to \%Vo2 max. Med.Sci.Sports.Exerc,29:410-414, 1997. 